\title{
An epidemiological investigation of training and injury patterns in British triathletes
}

\author{
P. K. Korkia MSc, D. S. Tunstall-Pedoe DPhil FRCP and N. Maffulli MD PhD \\ London Sports Medicine Institute, c/o Medical College of St. Bartholomew's Hospital, London, UK
}

\begin{abstract}
During the competitive season of 1990, 155 British triathletes whose competitive distances varied from sprint to full ironman, and who self-classified themselves as recreational, intermediate or élite, kept a training diary for an 8-week period. They gave details of injuries sustained while training for, or competing in, triathlons. The mean(s.d.) distances covered each week were: swimming, $4.2(2.6) \mathrm{km}$; cycling, $100.2(70.6) \mathrm{km}$; and running 23.4(15.2) km; mean(s.d.) training time was $7(3.4) \mathrm{h}$ per week, and a mean(s.d.) of 7.9(3.4) training sessions were completed per week. At least one injury was reported by $37 \%$ of the participants. The most frequently affected sites were the ankle/foot, thigh, knee, lower leg and the back. Overuse was the reported cause in $41 \%$ of the injuries, two-thirds of which occurred during running. The likelihood of an injury was positively associated with experience in triathlon. Average injury rate was 5.4 injuries per $1000 \mathrm{~h}$ of training $(95 \%$ confidence interval: 4-7.2) and 17.4 per $1000 \mathrm{~h}$ of competition (95\% confidence interval: 10.9-27.9). Injury incidence was unrelated to the mean amount of weekly training or competition, intensity or frequency of training.
\end{abstract}

Keywords: Triathlon, injuries, training

Previous studies of training and injury patterns in triathletes have been retrospective and have mainly involved subjects from North America. and New Zealand $^{1-5}$. For example O'Toole et al. studied ultradistance triathletes but were unable to show a relationship between training habits and the incidence and type of injury, whereas Williams et al. ${ }^{4}$ found a relationship between the weekly cycling distance and reported injuries. Levy et al. ${ }^{5}$ compared triathletes with single-sport athletes (in swimming, cycling and running) and found that triathletes averaged more hours of participation per week than any other group, and that they had a higher incidence of injury per year than single sport athletes.

In the present study, training and injury details were recorded prospectively over an 8-week period during the competitive season, between June and October 1990. The triathletes trained and competed over different distances (see Table 1) and at different levels of competence. Possible relationships were

Address for correspondence: Pirkko K. Korkia, London Sports Medicine Institute, c/o Medical College of St. Bartholomew's Hospital, Charterhouse Square, London EC1 6BQ, UK

(C) 1994 Butterworth-Heinemann Ltd 0306-3674/94/030191-06
Table 1. Approximate distances involved in triathlons $(\mathbf{k m})$

\begin{tabular}{lccc}
\hline Distance & Swimming & Cycling & Running \\
\hline Full ironman & 3.8 & 180 & 42 \\
Half ironman & 1.9 & 90 & 21 \\
Olympic distance & 1.5 & 40 & 10 \\
Sprint distance & $<1.5$ & $<40$ & $<10$ \\
\hline
\end{tabular}

examined between injuries and (1) the amount of training and competition; (2) intensity of training; (3) running surface; and (4) personal characteristics and background in triathlon.

\section{Subjects and methods}

\section{Recruitment}

A total of 730 questionnaires was distributed to triathletes: 258 directly by one of the investigators or via club secretaries; 250 by the National Triathlon Coach at competitions and a further 222 via traithlon clubs. In all, 580 started the questionnaire. Questionnaires were returned by club secretaries, or using self-addressed, stamped envelopes. The names and telephone numbers of 270 triathletes were supplied to us and they were contacted by telephone to provide encouragement and to answer any queries. A T-shirt was given to those who completed the study.

\section{Questionnaires}

The first part of the questionnaire collected data about personal details and background in triathlon.

The second part consisted of an 8-week training and injury diary. Athletes were asked to keep a record of their training and competitions, including the type of activity, intensity, mileage, duration, and the type of surface on which they trained. Space was allocated for recording rest days, occurrence of illness or a non-triathlon related injury, or any other comment.

The third part was for self-reporting of injuries associated with triathlon training or racing, sustained during the 8-week period. They were asked which body part(s) were injured, body tissue involved, nature of injury and how it happened. The investiga- 
tors acknowledge the difficulty involved with selfassessment of injuries by lay persons, and that such information must be viewed with caution.

A pilot questionnaire was tested over a 4-week period using nine subjects. The questionnaire was subsequently modified.

\section{Injury}

In this study, an injury was defined as an event which forced the athlete to: (1) stop the current training session or race, and prevented return to the session; (2) rest the day after injury; or which caused any of the following: injury to the eye, teeth or nerve; fracture; or concussion.

An acute injury was defined as an injury which arose because the integrity of the musculoskeletal system was broken by a single traumatic event. If no such event could be identified, the injury was classified as an overuse injury. They were asked to report which, if any, health professional gave first aid and follow-up treatment, how many days of training, competition and work were missed and which component sport(s) of triathlon had to be stopped because of the injury. The severity of an injury was assessed according to days lost from training, 7 days or fewer being minor, 8-21 days moderate and over 21 days severe.

\section{Statistical analysis}

The data were entered into dBASE III Plus ${ }^{6}$. Statistical analyses were done using the $\mathrm{SAS}^{7}$ and $\mathrm{GLIM}^{8}$ computer packages. Continuous data were analysed using analysis of variance, and binary and categorical data using logistic regression and log-linear models. Where the numbers were small, conditional exact tests were done ${ }^{9}$ including trend tests for ordered categories ${ }^{10}$. The injury rate analysis was done using Poisson regression in GLIM.

\section{Results}

\section{Characteristics of the sample}

Of the subjects, 124 were men and 31 were women, with a mean(s.d.) age of 34(8.9) and 32(7.3) years, respectively. Their height, weight, body mass index (BMI), main competitive distance and level of competence in triathlons is shown in Table 2. Of the athletes, $69 \%$ stated that they were from professional or semi-professional occupations. The majority $(47 \%)$ were from a running background, 19\% from swimming and $10 \%$ from a cycling background.

\section{Response rate}

The overall response rate was $29 \%$. It varied significantly between athletes recruited from clubs (48\% response rate) and those recruited at competitions (16\% response rate). The study included 155 correctly completed questionnaires; 12 incorrectly completed questionnaires were excluded from the study.

\section{Injuries during 8 weeks}

At least one injury was sustained by 58 triathletes (37\%) (45 men and 13 women) during the 8-week period. There was no difference in injury incidence between athletes recruited from clubs or at competitions. One injury was reported by 47 triathletes, ten reported two and one reported three injuries. Thirty six acute and 34 gradually developing injuries were recorded. Thirty seven injuries occurred during training and 19 during competition. In 14 cases no exact time could be identified.

Figure 1 shows injuries by site. Of the injured athletes, 27\% suffered ankle/foot, 20\% thigh, $19 \%$ knee, $16 \%$ lower leg and $14 \%$ back injuries.

The numbers of triathletes with each type of injury is shown in Figure 2. Forty per cent suffered injuries to muscle, $28 \%$ to ligament/joint, $15 \%$ tendon, $12 \%$ skin, $2 \%$ bone and $2 \%$ to other body tissues.

\section{Mechanism of injury}

Overuse was the reported cause of injury in $41 \%$ of cases, in $27 \%$ it was classified as 'other', $12 \%$ reported a twist and turn, $10 \%$ contact or collision and $9 \%$ overstretching. Of the injuries, $65 \%$ occurred during running, $16 \%$ while cycling and $12 \%$ while swimming.

\section{Treatment}

Professional help was sought immediately after the injury by $9 \%$ of the athletes (4\% from hospital accident and emergency, $4 \%$ from physiotherapist

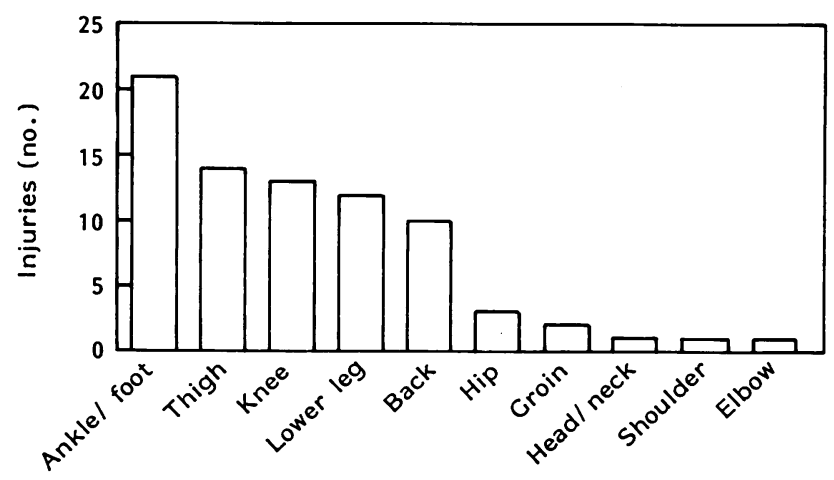

Figure 1. Injuries during 8 weeks $(n=80)$

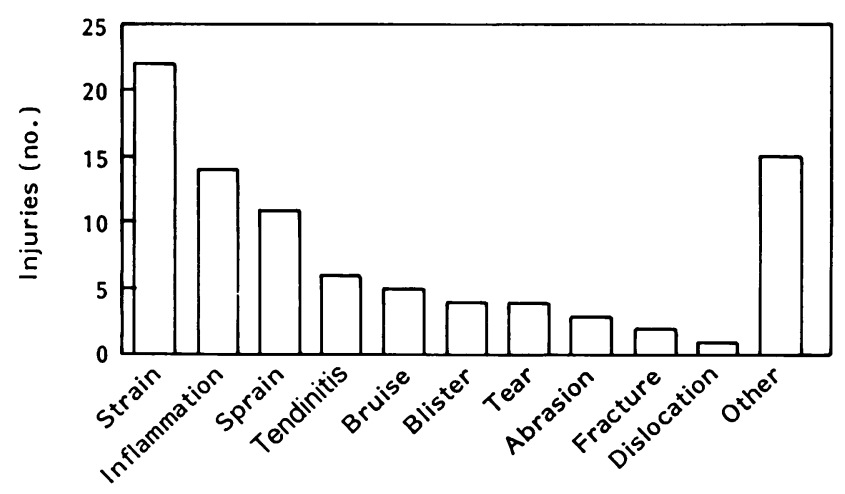

Figure 2. Type of injury $(\dot{n}=87)$ 


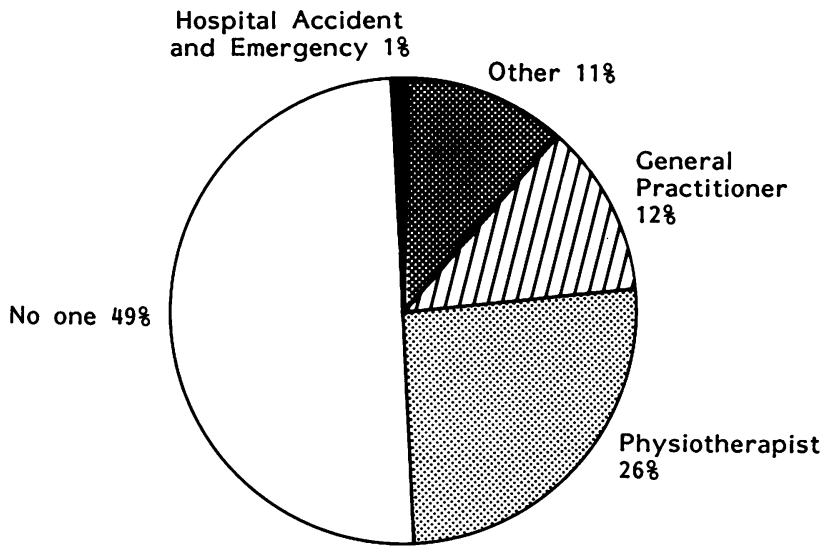

Figure 3. Follow-up treatment sought

and $1 \%$ from a general practitioner). The 'other' category mainly included nurses or manipulative therapists. Follow-up treatment was sought by $51 \%$ of all injured triathletes (Figure 3).

\section{Severity}

Of the reported injuries, $84 \%$ were minor, $13 \%$ moderate and 3\% severe. Running training had to be stopped by $78 \%$ of the injured triathletes, $37 \%$ stopped cycling and $21 \%$ swimming. Of the triathletes, $16 \%$ had to stop all three sports, $33 \%$ cycling and running, $18 \%$ swimming and running, and $16 \%$ swimming and cycling. Of the injuries, $83 \%$ did not result in missing a planned competition. Five injuries caused absence from work of up to 2 days.

\section{Characteristics of the sample and injuries}

Gender, age, height, weight, BMI, main competitive distance and level in triathlon are presented in
Table 2. These variables showed no evidence of association with injury incidence. No evidence of an association between the incidence of injury and background in any of the three disciplines of triathlon were found.

\section{Training habits and the incidence of injury}

Table 3 shows the average weekly training distances

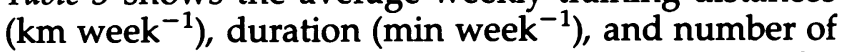
workouts per week in the three component sports for long-distance (ironman and half ironman) and shortdistance (olympic and sprint distances) triathletes. No statistical differences in training distance, time spent training or number of workouts per week, were found between men and women in short-distance triathletes. There was only one woman in the long-distance category, and therefore no gender comparison was made. Long-distance triathletes averaged a greater total weekly distance $\left(\mathrm{km} \mathrm{week}^{-1}\right)$ $(P=0.002)$, spent more time in training (min week $\left.{ }^{-1}\right)$ $(P=0.0002)$ and trained more frequently (times per week) $(P=0.0086)$ than short-distance triathletes. No evidence of an association was found between incidence of injury and amount of weekly training, time spent training or number of workouts per week for the whole group or subgroups of triathletes (in terms of level of competence and main competitive distance).

Training pace was not calculated, but the average time (in min week ${ }^{-1}$ ) spent doing intervals (including fartlek and repetition training), hard (including race pace), moderate, easy (including slow and recovery pace) and hill training, were recorded (Table 4). Note that training in the three disciplines has been combined. There was no evidence of an association between the intensity of training and the incidence of injury.

Table 2. Personal details

\begin{tabular}{|c|c|c|c|c|c|c|c|c|c|}
\hline \multirow[b]{2}{*}{ Sex } & \multirow[b]{2}{*}{ Age $(\text { years })^{*}$} & \multirow[b]{2}{*}{ Height $(\mathrm{cm})^{*}$} & \multirow[b]{2}{*}{ Weight $(\mathrm{kg})^{*}$} & \multirow[b]{2}{*}{$B M I^{*}$} & \multicolumn{2}{|c|}{ Competitive distance ${ }^{+}$} & \multicolumn{3}{|c|}{ Level of competence $^{t}$} \\
\hline & & & & & $\begin{array}{l}\text { Long } \\
\text { (no.) }\end{array}$ & $\begin{array}{l}\text { Short } \\
\text { (no.) }\end{array}$ & $\begin{array}{l}\text { Elite } \\
\text { (no.) }\end{array}$ & $\begin{array}{c}\text { Int } \\
\text { (no.) }\end{array}$ & $\begin{array}{l}\operatorname{Rec} \\
\text { (no.) }\end{array}$ \\
\hline $\begin{array}{l}M(\text { no. }=124) \\
F(\text { no. }=31)\end{array}$ & $\begin{array}{l}34(8.9) \\
32(7.3)\end{array}$ & $\begin{array}{c}176.7(17.7) \\
166.5(6.3)\end{array}$ & $\begin{array}{c}71.6(10.2) \\
58.0(5.9)\end{array}$ & $\begin{array}{l}22.6(2.8) \\
20.9(1.8)\end{array}$ & $\begin{array}{r}14 \\
1\end{array}$ & $\begin{array}{r}101 \\
27\end{array}$ & $\begin{array}{r}10 \\
3\end{array}$ & 99 & 14 \\
\hline
\end{tabular}

*Values are mean(s.d.); ${ }^{\dagger}$ not all subjects could be classified according to competitive distance or level of competence; BMI, weight $(\mathrm{kg}) /$ height $(\mathrm{m})^{2}$; Int, intermediate; Rec, recreational

Table 3. Weekly training

\begin{tabular}{|c|c|c|c|c|}
\hline & & Swimming* & Cycling* & Running* \\
\hline Distance $\mathrm{km}$ week $^{-1}$ & $\begin{array}{l}\text { long }^{+} \\
\text {short }^{\ddagger}\end{array}$ & $\begin{array}{l}5.8(3.0) \\
4.1(2.5)\end{array}$ & $\begin{array}{r}151.7(69.8) \\
95.2(69.2)\end{array}$ & $\begin{array}{l}29.7(19.7) \\
22.2(12.8)\end{array}$ \\
\hline 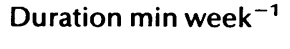 & long & $153.4(62.4)$ & $322.2(132.1)$ & $132.7(83.9)$ \\
\hline Workouts (no.) & $\begin{array}{l}\text { short } \\
\text { long } \\
\text { short }\end{array}$ & $\begin{array}{c}101.3(55.1) \\
3.1(1.3) \\
2.4(1.2)\end{array}$ & $\begin{array}{c}195.0(133.2) \\
4.3(2.6) \\
2.8(2.0)\end{array}$ & $\begin{array}{c}105.1(60.3) \\
2.6(1.4) \\
2.6(1.2)\end{array}$ \\
\hline
\end{tabular}

${ }^{*}$ Values are mean(s.d.); ${ }^{\dagger}$ no. $=15 ;{ }^{*}$ no. $=128$ 
Table 4. Time spent in different types of training $\left(\mathrm{min} \mathrm{week}^{-1}\right)$

\begin{tabular}{lccccc}
\hline & Intervals & Hills & Hard & Moderate & Easy \\
\hline Long & $99(76)$ & $3(5)$ & $137(87)$ & $278(217)$ & $86(112)$ \\
Short & $72(67)$ & $4(11)$ & $80(73)$ & $195(124)$ & $53(56)$ \\
\hline
\end{tabular}

Values are mean(s.d.)

Triathletes did $68 \%$ of running training on roads. Time spent running on hard or soft surfaces did not influence the incidence of injury.

Of triathletes, $30 \%$ had practised the sport for over 4 years, $21 \%$ between 2 and 3 years, $20 \%$ between 1 and 2 years, $19 \%$ between 3 and 4 years, and $11 \%$ for less than one year. There was an association between experience in triathlon and the incidence of injury (trend test, $P=0.02$ ). The rate of injury increased with the amount of time the sport had been practised. Of those who had trained in triathlons for longer than 4 years, $45 \%$ sustained at least one injury during the 8 weeks, as opposed to $33 \%$ of those who had trained between 2 to 3 years, and $14 \%$ of those who had trained for 1 year or less. Using logistic regression analysis an association was still evident when experience was adjusted for age and running distance $\left(\mathrm{km}\right.$ week $\left.{ }^{-1}\right)(P=0.04)$.

Training load had been increased appreciably by $37 \%$ of all triathletes in the 6-week period before participating in the study. No evidence of an association was found between onset of injury and increase in training loads.

Strength training was practised regularly by $57 \%$ of the men and $65 \%$ of the women during at least one training phase in the year. Post-exercise stretching, warm-up and cool-down frequencies are described in Table 5, which shows that the majority practised these fairly regularly. Most (94\%) used the static stretching method. Participation in strength training, stretching, warm-up and cool-down habits did not influence the incidence of injury.

\section{Competition}

The short- and long-distance triathletes spent a mean(s.d.) (range) of 46(43) (0-202) and 53(45) (0-134) min competing per week, respectively. The time spent competing was not found to be associated with the incidence of injury.

Table 5. Warm-up, cool-down and post-exercise stretching habits

\begin{tabular}{lccc}
\hline & $\begin{array}{c}\text { Always/very } \\
\text { often } \\
(\%)\end{array}$ & $\begin{array}{c}\text { Often/ } \\
\text { occasionally } \\
(\%)\end{array}$ & $\begin{array}{c}\text { Seldom/ } \\
\text { never } \\
(\%)\end{array}$ \\
\hline Warm-up & 26 & 44 & 30 \\
$\begin{array}{l}\text { Cool-down } \\
\text { Post-exercise } \\
\text { stretching }\end{array}$ & 43 & 37 & 20 \\
\hline
\end{tabular}

\section{Injury rate}

The injury rate was 5.4 injuries per $1000 \mathrm{~h}$ of training (95\% confidence interval, 4.0-7.2) with 37 injuries reported during training, and 17.4 per $1000 \mathrm{~h}$ of competition (95\% confidence interval, 10.9-27.9) with 19 injuries reported during competitions. There was no evidence of a difference between injury rates in long- and short-distance triathletes $(P=0.47)$.

\section{Injuries in the past year}

Seventy four triathletes $(47 \%)$ reported an injury in the year before taking part in the present survey. Thirty eight per cent of all injuries affected the ankle/foot, $32 \%$ the knee and $22 \%$ the lower leg (Figure 4). Of the three most common injuries, 35\% involved a strain, $25 \%$ tendinitis and $22 \%$ a tear. No statistically significant differences regarding the type of injury were found between men and women. The athletes who had sustained an injury in the past year were also more likely to sustain an injury during the 8 -week study period $(P<0.0001)$.

Sixty five per cent of triathletes with any one, or a combination of, the following injuries: ankle/foot; knee; lower leg; thigh; and back injury; during the 8-week period, also had sustained an injury to one or more of these sites in the year before participating in the present study $\left(\chi^{2}\right.$ test, $\left.P=0.014\right)$. To take into account small numbers, the conditional exact test was also used. This confirmed the above findings $(P=0.012)$. In contrast, only $42 \%$ of triathletes who had sustained injuries to the four above mentioned sites in the past year injured 'other' sites during the 8 -week period. Those $32 \%$ with 'other' injuries during the 8-week period also tended to have sustained injuries from the same anatomical group in the past year.

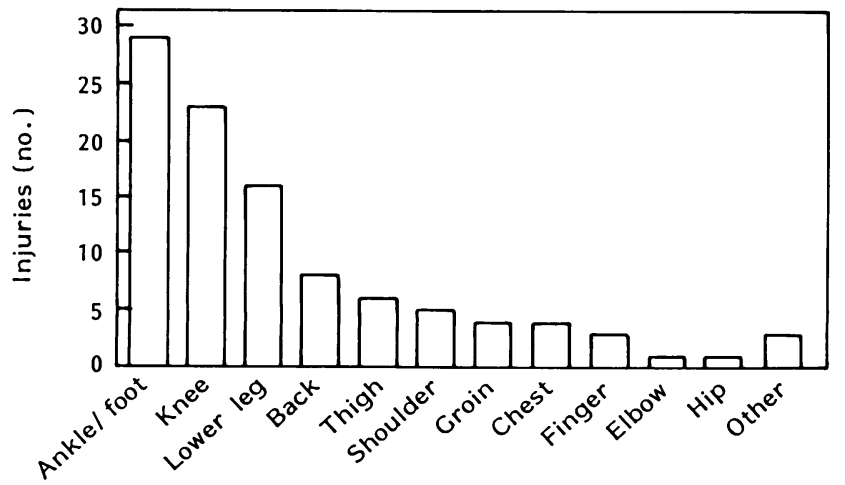

Figure 4. Injuries in the previous year $(n=103)$ 


\section{Discussion}

The analysis of the records returned by the triathletes taking part in this study is dependent on the sampling method used, and is thus open to bias. When questionnaires are distributed on training nights and in competitions, triathletes who are ill or injured may not be sampled. An opposite bias would be introduced if the injured triathlete perceived the survey to be valuable and were more likely to take part than the non-injured athlete. The present results can therefore only be viewed as indicative of a subgroup of triathletes approached, who were prepared to partake in the study. Another major consideration relates to self-reporting of injuries, particularly the assessment of type of injury and body tissue affected.

In accordance with other recent studies on triathletes $^{2-4,11}$, the great majority of athletes in this study came from a running background $(47 \%)$, followed by swimming $(19 \%)$ and cycling $(10 \%)$. The incidence of injury was positively associated with experience in triathlon and similar data have been reported for competitive triathletes ${ }^{4}$ and for runners ${ }^{12}$.

The frequency of injury has been found to increase in runners during the spring and summer when training and competition are most intense ${ }^{13}$. Of our subjects, $37 \%$ indicated that they had increased their training load appreciably in the 6-week period before participating in the study. Although not associated with injuries, this may play a part in the fairly high percentage reporting injuries in an 8-week period when compared with other recent studies of triathletes $^{2,4,11}$. Elite triathletes training for the longer distances may train around $800 \mathrm{~h}$ per year, therefore an average of 5.4 injuries per $1000 \mathrm{~h}$ training is fairly high. It is possible, however, that prospective, self-reporting study participants may be more likely to report minor injuries than those in retrospective studies $^{14}$.

The most commonly injured sites were the ankle/foot, thigh, knee, lower leg and back. Other studies on triathletes have reported the knee to be the most commonly injured part with foot/ankle injuries being frequent $t^{1-4,11}$. Studies of cyclists have shown that problems with the knees, foot/ankle and neck/shoulder areas are common ${ }^{15}$ as is 'pain and discomfort' in the lower back ${ }^{16}$. Variation in the methods of defining and grouping injuries complicates comparisons. It is clear, however, that most of the injuries occur in the lower extremity, although some studies have shown that shoulder injuries are frequent ${ }^{2,4}$. We were surprised that only one shoulder injury was reported despite the considerable amount of swimming training done by some triathletes. Shoulder injuries tend to be prominent in swimmers ${ }^{17}$.

In accordance with previous studies ${ }^{1-3,11,18}$, we found that soft tissue injuries involving strain (25\%), inflammatory pain $(16 \%)$, sprain $(13 \%)$ and tendinitis (7\%) were most common with only two fractures recorded. Overuse was the mechanism of injury reported most often. However, in $27 \%$ of the cases, the mechanism was categorized as 'other', probably reflecting the difficulty in self-assessing, injuries.
Most of the injuries occurred during running $(65 \%)$, followed by cycling $(16 \%)$ and swimming $(11 \%)$, confirming that running is the component sport of triathlon responsible for many of the injuries.

The incidence and type of injury and average weekly training distances in running, swimming or cycling were not found to be associated in the overall group of triathletes, or in subgroups (such as élite, intermediate and recreational; short- and longdistance competitors). Triathletes' training distances in this study are consistently lower than those reported in other studies, $1,11,19$. The above studies may reflect training habits of a more selected group of athletes, but it is also possible that recall difficulties may have resulted in estimation errors. In theory, training distances should be reduced during the competitive season, when triathletes focus on competitions and speed work. Most other studies on triathletes have found no relationship between the amount of training and injury incidence ${ }^{1-4,11}$, contrary to the findings of many running studies ${ }^{20-23}$.

$\mathrm{O}^{\prime}$ Toole et al. $^{1}$ who found that most triathletes $(72 \%)$ in their study had sustained multiple injuries suggested that continued training despite injury may exacerbate the condition in proportion to training distance, pace and/or time. Running studies have also shown that previous injury is predictive of risk of injury ${ }^{24-26}$, with a symmetrical lower limb configuration being a protective factor ${ }^{27}$. The number of multiple injuries during the 8-week study period was small (11 athletes), but they appeared in 'clusters'. Biomechanical interdependency in the locomotor system may influence structures below and above the injured site ${ }^{28}$, and structures on the contralateral side, contributing to injuries of other areas when training is maintained despite injury.

It is of note that Williams et al. ${ }^{4}$ reported that triathletes with a cycling background sustained fewer injuries than those from non-cycling backgrounds. They suspected that an increase in training mileage, rather than the actual mileage itself may be responsible for injuries. It may be difficult to pinpoint the factors responsible for injury in a heterogeneous sample participating in a multisport event. In triathlon, injuries can be expected to be influenced by factors such as technique, equipment, body alignment and training errors and therefore studies of training habits and injuries in more homogeneous groups of triathletes over a longer period of time may prove more useful.

Running speed has been linked with an increased incidence of injury in runners by some investigators $^{29-30}$, but not by others ${ }^{20,23}$. Like us, O'Toole $e t$ $a{ }^{1}{ }^{1}$ found no association between injury incidence and training pace in ultradistance triathletes. Massimo et al. $^{11}$ noted that cycling pace may influence the occurrence of overuse injuries in the foot, ankle and Achilles tendon.

The injury rate per $1000 \mathrm{~h}$ of competition was high at 17.4. Because of the relatively shorter time spent in competition, the $95 \%$ confidence interval is large, and the estimate is therefore less accurate than that for training.

Triathletes in the present investigation were reluctant to seek professional help immediately after 
injury. Of the $51 \%$ who sought follow-up treatment, $20 \%$ consulted a physiotherapist and $12 \%$ a general practitioner. In a North American study, $70 \%$ of injured triathletes saw a medical professional following an injury: $48 \%$ saw a doctor, $13 \%$ a physiotherapist and a further $13 \%$ a podiatrist ${ }^{3}$. The reasons for such a low consultation rate among British triathletes is unclear. No specific enquiries were made, so reasons are only speculative. On the one hand, athletes may feel that they do not warrant prompt professional attention, as the injury is perceived as minor. On the other, as in the UK sports medicine is not practised as a hospital speciality as yet, they may think that health care professionals are, in general, not equipped to deal with triathletes. The denial of the severity of an injury may be due to the fear of loss of training time. Economical and psychological reasons may also play a role.

\section{Acknowledgements}

We wish to thank Dr Mike Kenward, Applied Statistics Department, University of Reading, Ms Vanessa Leary and Sally Dixon, London Sports Medicine Institute, for their valuable help.

\section{References}

1 O'Toole ML, Hiller DB, Smith RA, Sisk TD. Overuse injuries in ultradistance triathletes. Am I Sports Med 1989; 17: 514-18.

2 Collins K, Wagner M, Peterson K, Storey M. Overuse injuries in triathletes: a study of the 1986 Seafair Triathlon. Am J Sports Med 1989; 17: 675-80.

3 Ireland ML, Micheli LJ. Triathletes: biographic data, training, and injury patterns. Annals of Sports Medicine 1987; 3: 117-120.

4 Williams MM, Hawley JA, Black R, Freke M, Simms K. Injuries amongst competitive triathletes. New Zealand Journal of Sports Medicine 1988; (March): 2-5.

5 Levy CM, Kolin E, Berson BM. The effect of cross training on injury incidence, duration and severity (part 2). Sports Med Clin Forum 1986; 3: 1-8.

6 dBASE III Plus. Version 1.1, Culver City, USA: Ashton-Tate 1985, 1986.

7 SAS.SAS/STAT Guide to Personal Computers. Version 6, SAS Institute, Cary, North Carolina, USA, 1987.

8 GLIM Numerical Algorithm Group, Oxford, UK 1977.
9 Agresti A. Categorical Data Analysis. New York, USA: Wiley, 1990.

10 Armitage P, Berry G. Statistical Methods in Medical Research 2nd ed. Oxford, UK: Blackwell Scientific Publications, 1987.

11 Massimo FA, Armstrong MA, O'Toole ML, Hiller WD, Laird RH. Common triathlon injuries: special considerations for multisport training. Annals of Sports Medicine 1988; 4: 82-6.

12 Pagliano JW, Jackson DW. A clinical study of 3,000 long-distance runners. Annals of Sports Medicine 1987; 3: 88-91.

13 Lysholme J, Wiklander J. Injuries in runners. Am J Sports Med 1987; 15: 168-71.

14 Hunter RE, Levy IM. Sports Injury Research. Am J Sports Med 1988; 16(Suppl.1): S-36.

15 Weiss BD. Nontraumatic injuries in amateur long distance bicyclists. Am J Sports Med 1985; 13: 187-92.

16 Bohlman JT. Injuries in competitive cycling. Physician and Sportsmedicine 1981; 9: 117-24.

17 Richardson AB, Jobe FW. The shoulder in competitive swimming. Am I Sports Med 1980; 8: 159-63.

18 O'Toole ML, Massimo FA, Hiller WDB, Laird RH. Medical considerations in triathletes: the 1984 Hawaii Ironman triathlon. Annals of Sports Medicine 1987; 3: 121-3.

19 O'Toole ML. Training for ultraendurance triathlons. Med Sci Sports Exerc 1989; 21: S209-S213.

20 Blair SN. Risk factors and running injuries. Med Sci Sports Exerc 1985; 17: xii.

21 Jacobs SJ, Berson BL. Injuries to runners: a study of entrants to a 10,000 meter race. Am J Sports Med 1986; 14: 151-55.

22 James SL, Bates BT. Östering LR. Injuries in runners. Am J Sports Med 1981; 6: 40-50.

23 Koplan JP, Powell KE, Sikes RK, Shirley RW, Campbell CC. An epidemiologic study of the benefits and risks of running. JAMA 1982; 248: 3118-21.

24 Marti B, Vader JP, Minder CE, Abelin T. On the epidemiology of running injuries: the 1984 Bern Grand-Prix study. Am J Sports Med 1988; 13: 285-93.

25 Walter SD, Hart LE, McIntosh JM, Sutton JR. The Ontario cohort study of running-related injuries. Arch Intern Med 1989; 149: 2561-4.

26 Taimela S, Kujala UM, Österman K. Intrinsic risk factors and athletic injuries. Sports Med 1990; 9: 205-15.

27 Friberg O, Kvist M. Leg length inequality in athletes. In: Bachl et al. eds. Current Topics in Sports Medicine. Vienna, Austria: Urban and Schwarzenberg, 1984: 984-92.

28 Molnar ME. Rehabilitation of the injured ankle. Clin Sports Med 1988; 7: 193-204.

29 Kirby KA, Valmassy RL. The runner-patient history. What to ask and why. I Am Podiatry Assoc 1983; 73: 39-43.

30 Pollock ML, Cureton TK, Greinger L. The effect of frequency of training on work capacity, cardio-vascular function and body composition in adult men. Med Sci Sport 1969; 1: 70-4. 